\title{
Polissacarídeos Extraídos da Gabiroba (Campomanesia xanthocarpa Berg): Propriedades Químicas e Perfil Reológico
}

\author{
Marli da S. Santos \\ Tecnologia de Alimentos, UFPR
}

\author{
Carmen L. 0. Petkowicz \\ Departamento de Bioquímica, UFPR
}

\author{
Charles W. I. Haminiuk \\ Tecnologia de Alimentos, UFPR/UTFPR - Campo Mourão
}

\author{
Lys Mary B. Cândido \\ Tecnologia de Alimentos, UFPR /UTFPR - Francisco Beltrão
}

\begin{abstract}
Resumo: A Campomanesia xanthocarpa Berg (Myrtaceae) é uma frutífera nativa brasileira, com ampla distribuição natural na região Sul. Embora apresente frutificação abundante, produza frutos com características sensoriais e nutricionais atrativas, esses não são coletados e se perdem nos campos. Neste trabalho, a polpa do fruto sem semente (1500 g) foi triturada em etanol / água na proporção de 1:4 (v/v), refluxada por 15 minutos em temperatura de ebulição. O resíduo obtido foi submetido a extrações sequenciais. As extrações foram otimizadas utilizando um planejamento fatorial $2^{2}$, tendo como variáveis a concentração do ácido cítrico $(0,5$ e $5 \%)$ e a temperatura $\left(50\right.$ e $\left.100{ }^{\circ} \mathrm{C}\right)$. Os polissacarídeos provenientes de diferentes extrações foram caracterizados quanto à composição química e perfil reológico. Os altos teores de ácidos urônicos, arabinose e galactose detectados em todas as frações, indicam que estas são constituídas por polissacarídeos pécticos. Os polissacarídeos extraídos da polpa da gabiroba apresentaram um comportamento pseudoplástico. Todas as frações apresentaram como característica resistência frente às variações de temperatura. Quando submetidas a ciclos de aquecimento e posterior resfriamento estes géis retornam à sua estrutura original.
\end{abstract}

Palavras-chave: Pectina, reologia, composição química.

\section{Polysaccharide Isolated From Gabiroba (Campomanesia xanthocarpa Berg): Chemical Properties and Rheology Profile}

\begin{abstract}
The Campomanesia xanthocarpa Berg (Myrtaceae) is a Brazilian native fruit, widely abundant in the Southern region. Despite their large fructification, in addition to nutritional and attractive sensory characteristics, these fruits are not collected, being lost in the fields. In this work, the fruit pulp without seed (1500 g) was crushed in ethanol/water at a ratio of 1:4 (v/v), refluxed for $15 \mathrm{minutes}$ at boiling temperature. The residue obtained was subjected to sequential extractions. The extractions were optimized using a factorial design $2^{2}$, with the concentration of citric acid $(0.5$ and $5 \%)$ and temperature $\left(50\right.$ and $\left.100{ }^{\circ} \mathrm{C}\right)$ as variables. The polysaccharides were characterized according to their chemical composition and rheological profile. The high concentrations of uronic acids, arabinose and galactose, detected in all fractions, indicate that they consist of pectin. The results showed that the extraction method was efficient for fractionation of pectin from different areas of the cell wall. The polysaccharides extracted from the fruit pulp of gabiroba showed a pseudoplastic behavior. All the fractions were resistant to temperature variations. When these gels are heated up and cooled down, they adopt their original structure.
\end{abstract}

Keywords: Pectin, rheology, chemical composition.

\section{Introdução}

Pectinas são heteropolissacarideos complexos encontrados na parede celular primária e nas camadas intercelulares dos vegetais. Estão associadas aos polissacarídeos estruturais, contribuindo para adesão entre as células e para a resistência mecânica da parede celular ${ }^{[1]}$. Estruturalmente, as pectinas são constituídas por uma cadeia principal linear de unidades repetidas de ácidos D-galacturônicos unidas por ligações $\alpha(1 \rightarrow 4)$, onde parte dessas unidades pode apresentar-se esterificada. As cadeias lineares são intercaladas por unidades de $(1 \rightarrow 2)$ - $\alpha$-L-ramnose, que servem de pontos de ligações para as cadeias laterais, formadas por açúcares neutros, principalmente D-galactose, L-arabinose e L-rhamnose. As pectinas são subdivididas em dois grupos, um com alto grau de metoxilação (HM) onde apresentam mais de $50 \%$ dos seus grupos carboxílicos esterificados e outro com baixo grau de esterificação (LM) as que apresentam menos de $50 \%$ dos seus grupos carboxílicos esterificados ${ }^{[2]}$.

As pectinas de alto grau de metoxilação gelificam em presença de altas concentrações de sólidos solúveis, geralmente superiores a $55 \%$ e valores de $\mathrm{pH}$ de 2,0 a $3,5^{[3]}$. Este gel se estabiliza por interações hidrofóbicas entre os grupos éster metílicos e por

Autor para correspondência: Marli da S. Santos, Programa de Pós-graduação em Tecnologia de Alimentos, Universidade Federal do Paraná, Centro Politécnico, Av. Coronel Francisco Heráclito dos Santos, 100, Jardim das Américas, CP 19011, CEP: 81531-980, Curitiba, PR, Brasil. E-mail: marli.sisantos@bol.com.br 
formação de pontes de hidrogênio. A adição de sólidos solúveis diminui a atividade e disponibilidade de água livre para solvatar os polissacarídeos, os aproxima e facilita interações hidrofóbicas entre os grupos éster metílicos ${ }^{[4]}$. As pectinas de baixo grau de metoxilação formam géis na presença de cálcio e outros íons divalentes. A gelificação é devida à formação de zonas de junção intermolecular entre as regiões homogalacturônicas de diferentes cadeias, de acordo com o modelo egg box ${ }^{[5]}$.

As pectinas são polissacarídeos muito utilizados industrialmente, principalmente em produtos alimentícios, aos quais são adicionados em pequenas quantidades.

Embora as pectinas façam parte da maioria dos tecidos vegetais, o número de fontes utilizadas comercialmente é muito limitado. Diante deste contexto, existe interesse em caracterizar novas fontes de obtenção de pectinas.

No Brasil existe abundância de frutos nativos, muitos dos quais não são aproveitados. Esses frutos poderiam ser utilizados como matéria prima para as agroindústrias. Neste trabalho foram investigados os polissacarídeos presentes nos frutos da Campomanesia xanthocarpa Berg que é uma frutífera nativa brasileira, pertencente à família Myrtaceae com ampla distribuição natural na região Sul do Brasil. Floresce durante os meses de setembro e outubro, produzindo frutos com características sensoriais e nutricionais atrativas, que amadurecem a partir de novembro. Embora apresentem frutificação expressiva, esses frutos não são coletados e se perdem nos campos ${ }^{[6]}$.

O objetivo deste trabalho foi avaliar as características físicoquímicas e reológicas das pectinas extraídas da polpa de gabiroba. $\mathrm{O}$ isolamento dos polissacarídeos da parede celular do fruto da Campomanesia xanthocarpa Berg, foi realizado através de extração sequencial dos polissacarídeos procurando aplicar métodos e solventes que causem um mínimo de degradação nos polímeros, a fim de elucidar as características estruturais dos polissacarídeos presentes na parede celular desse fruto.

\section{Experimental}

\section{Material vegetal}

Os frutos de Campomanesia xanthocarpa Berg, que são encontrados em populações de plantas de forma espontânea e dispersos, foram coletados nodistritode Itaiacoca, localizadopróximo ao município de Ponta Grossa, PR, situado a aproximadamente $975 \mathrm{~m}$ de altitude, apresentando como coordenadas geográficas $25^{\circ} 05^{\prime} 42$ 'de latitude sul e $50^{\circ} 09^{\prime} 43^{\prime \prime}$ de longitude.

\section{Métodos}

Para a extração dos polissacarídeos foram removidas as sementes do fruto com a ajuda de uma espátula pequena. A polpa do fruto da C. xanthocarpa Berg sem semente (1500 g) foi misturada em etanol/ água na proporção de 1:4 (v/v), triturada em um homogeneizador, refluxada por 15 minutos em temperatura de ebulição para inativação de enzimas endógenas, seguida de resfriamento em banho de gelo e filtrada em filtro sintético para obtenção do resíduo insolúvel em álcool (RIA), material de partida para obtenção dos polissacarídeos. Após a filtragem, o RIA foi submetido à centrifugação por quatro vezes (15400 xg por 20 minutos) e desidratado em estufa a vácuo (Q819V-Marca Quimis) até massa constante.

As extrações foram otimizadas, utilizando um planejamento fatorial $2^{2}$, e um tempo de extração de 60 minutos em todos os experimentos, tendo como variáveis a concentração do ácido cítrico $(0,5$ e $5 \%)$ e a temperatura $\left(50\right.$ e $\left.100^{\circ} \mathrm{C}\right)$. As extrações foram realizadas em agitador mecânico da marca Fisaton modelo 713.
Após cada extração, as dispersões foram centrifugadas a $15400 \mathrm{xg}$ por 20 minutos, separando o sobrenadante do resíduo, que foi utilizado para as extrações subsequentes. Os polissacarídeos foram precipitados a partir dos sobrenadantes, que foram concentrados até $50 \mathrm{~mL}$ e adicionados de dois volumes de etanol 95\% (100 mL) e mantidos sob refrigeração por 24 horas para precipitação dos polissacarídeos. Após filtração em filtro de poliéster, o material precipitado foi lavado três vezes com etanol absoluto e desidratado em estufa a vácuo (Q819V- Marca Quimis) até peso constante, originando a respectiva fração. $\mathrm{O}$ rendimento das extrações foi calculado em relação ao resíduo insolúvel em álcool.

As frações foram analisadas quanto ao seu teor em açúcar total, ácidos urônicos e proteínas. Todas as análises foram efetuadas em triplicata. A absorbância foi medida em espectrofotômetro UV-VIS Shimadzu Multispec 1501. Açúcares totais foram determinados pelo método fenol-ácido sulfúrico ${ }^{[7]}$, em comprimento de onda de $490 \mathrm{~nm}$, utilizando como padrão solução de glucose nas concentrações de 20 a $70 \mu \mathrm{g} \cdot \mathrm{mL}^{-1}$. A dosagem de ácidos urônicos foi realizada através do método descrito por Filisetti-Cozzie Carpita ${ }^{[8]}$ com algumas modificações. Em $400 \mu \mathrm{L}$ de amostra solubilizada foram adicionados $40 \mu \mathrm{L}$ de solução de ácido sulfâmico sulfamato de potássio 4 mol.L ${ }^{-1}$ em pH 1,6 (dissolução de 3,81 g de ácido sulfâmico em 100 mL de água destilada, acertando o pH com solução saturada de hidróxido de potássio onde foram acrescentados $2,4 \mathrm{~mL}$ de solução de tetraborato de sódio $75 \mathrm{mM}$, ácido sulfúrico concentrado (resfriado em banho de gelo). Após o resfriamento os tubos de ensaios foram aquecidos em banho maria a $100{ }^{\circ} \mathrm{C}$ por 20 minutos. Esta mistura foi resfriada e em seguida foram adicionados $80 \mu$ da solução de $m$-hidroxi-bifenil (Sigma) a $0,15 \%$ em $\mathrm{NaOH} 0,5 \%$ para a produção do complexo colorido que foi lido em $525 \mathrm{~nm}$. A quantificação foi realizada com o auxílio de uma curva padrão de ácido galacturônico (Sigma) dentro da sensibilidade do método $(20$ a $100 \mu$ g de ácido urônico). Os teores de proteínas foram determinados pelo método de Hartree ${ }^{[9]}$ sendo a leitura efetuada em $650 \mathrm{~nm}$. O padrão empregado foi soro albumina bovina (BSA-SIGMA) nas concentrações de 20 a $80 \mu \mathrm{g} . \mathrm{mL}^{-1}$.

Para a determinação da composição monossacarídica, os polissacarídeos foram hidrolisados com ácido trifluoracético 2 mol.L ${ }^{-1}$ em tubo hermeticamente fechado, a $100{ }^{\circ} \mathrm{C}$ em estufa Fanem, modelo Orion com controlador A-HT por cinco horas ${ }^{[10]}$. O ácido remanescente foi removido do hidrolisado através de evaporação. Os monossacarídeos resultantes da hidrólise ácida total foram reduzidos com boroidreto de sódio $\left(\mathrm{NaBH}_{4}\right)$ durante duas horas para promover a redução dos grupamentos carboxilicos dos monossacarídeos e formar os alditóis ${ }^{[11]}$.

O excesso do agente redutor foi decomposto e os cátions sódio removidos pela adição de resina trocadora de cátions (Lewatit) na forma ácida. A solução foi filtrada em algodão e após esta etapa o material foi evaporado até a secura, com fluxo de nitrogênio, seguido de três lavagens consecutivas de metanol para remoção do boro remanescente por co-destilação, na forma de borato de trimetila. Os alditóis resultantes foram acetilados pela adição de piridina que atua como agente catalisador e anidrido acético na proporção de 1:1 (v/v) durante aproximadamente 16 horas em tubo de hidrólise hermeticamente fechado em temperatura ambiente $\left(27 \pm 2{ }^{\circ} \mathrm{C}\right)$. Esta reação foi interrompida pela adição de gelo moído dentro dos tubos.

Os acetatos de alditóis foram extraídos com $1 \mathrm{~mL}$ de clorofórmio. A piridina residual foi complexada com solução aquosa de sulfato de cobre $\left(\mathrm{CuSO}_{4}\right)$ a $5 \%(\mathrm{~m} / \mathrm{v})$, sendo assim separada da fase clorofórmica e eliminada por sucessivas e intercaladas lavagens com água destilada e $\mathrm{CuSO}_{4}$. A fase clorofórmica contendo os acetatos de alditóis foi coletada, e após secura, a amostra foi ressolubilizada em 
acetona para ser analisada por cromatografia líquido-gasosa (GLC). As análises por GLC foram efetuadas em cromatógrafo gasoso Hewlett Packard modelo 5890 A Série II, com detector de ionização de chama (FID) e injetor à temperatura de $250{ }^{\circ} \mathrm{C}$, coluna capilar DB-210 (30 $\mathrm{m} \times 0,25 \mathrm{~mm}$ de diâmetro interno), com espessura de filme de $0,25 \mu \mathrm{m}$ a $220{ }^{\circ} \mathrm{C}$, e nitrogênio como gás de arraste em fluxo de $2,0 \mathrm{~mL} / \mathrm{min}^{[12]}$.

O grau de esterificação das pectinas foi determinado por espectroscopia de infravermelho (FT-IR - Fourier transform-infrared), em espectrofotômetro BOMEM MB-100. Os espectros foram coletados no modo de transmitância e na faixa de números de ondas 4000-400 $\mathrm{cm}^{-1}$, com resolução de $4 \mathrm{~cm}^{-1}, 32$ scans, empregando amostras sólidas pulverizadas. Foram preparadas pastilhas de brometo de potássio 90:10 (m/m) de KBr/amostra. Como branco foi utilizado pastilha de $\mathrm{KBr}$, para correção da absorção do $\mathrm{CO}_{2}$ e mistura de ar antes das análises. As áreas dos picos correspondentes aos grupos carboxílicos esterificados e não esterificados foram obtidas utilizando o software do equipamento. Para a análise de FT-IR, foi utilizado padrões de pectinas Sigma com diferentes graus de esterificação: 22, 67 e 89. O grau de esterificação foi calculado pela equação: área COO-R / (área COO-R + área COO-H) x 100, com cálculo das áreas das bandas em torno de 1741 e $1635 \mathrm{~cm}^{-1}$ correspondentes aos ácidos urônicos esterificados e livres, respectivamente. Para a pesagem dos polissacarídeos e do KBr utilizou-se uma balança analítica Radwag, com precisão de $0,0001 \mathrm{~g}^{[13]}$.

O perfil reológico das amostras foi determinado em reômetro HAAKE RS 75 Rheoestress, acoplado a um controlador de temperatura Peltier (TC81) utilizando sensor cone-placa (C60 2 Ti). Previamente às análises reológicas, foi determinada a inércia para descontar os valores das forças centrífugas e centrípetas geradas durante os experimentos. Durante as análises, a temperatura ambiente manteve-se em $20 \pm 1{ }^{\circ} \mathrm{C}$. Para a obtenção dos géis os polissacarídeos pulverizados e o açúcar foram dissolvidos em solução de $\mathrm{NaCl}$ 0,1mol.L ${ }^{-1}$ com agitação por aproximadamente 24 horas à temperatura ambiente $\left(28 \pm 2{ }^{\circ} \mathrm{C}\right)$. Após a dissolução, o pH da suspensão foi ajustado para 4,0 e adicionado cloreto de cálcio na relação $\left[2\left(\mathrm{Ca}^{+2}\right) /\left(\mathrm{COO}^{-}\right)\right]$para obter-se a razão $\mathrm{R}=0,58$ seguido de aquecimento a $80{ }^{\circ} \mathrm{C}$ sob agitação por 10 minutos ${ }^{[14]}$. O gel foi mantido refrigerado a até o momento da análise. Inicialmente realizou-se uma varredura de tensão na frequência de $1 \mathrm{~Hz}$ para verificação da faixa viscoelástica linear e seleção da tensão ou deformação que seriam empregadas nas análises de varredura de frequência e rampas de temperatura, de modo a preservar a estrutura do gel em análise. As varreduras de frequência foram conduzidas na tensão ou deformação pré-selecionada, aumentando a frequência oscilatória com o tempo, na faixa de 0,1-10 Hz. As curvas de fluxo foram realizadas a $25^{\circ} \mathrm{C}$ na faixa de $0,1-500 \mathrm{~s}^{-1}$. Durante as análises, a temperatura ambiente foi mantida a $25^{\circ} \mathrm{C}$. As amostras também foram avaliadas frente a variações de temperatura utilizando um programa de aquecimento de $1{ }^{\circ} \mathrm{C} / \mathrm{min}$, nas temperaturas crescentes de $5-100{ }^{\circ} \mathrm{C}$ em 2200 segundos, seguida de resfriamento de $100-5{ }^{\circ} \mathrm{C}$ em 2200 segundos, em frequência fixa de $1 \mathrm{~Hz}$. Para prevenir a evaporação do solvente foi aplicada uma camada de óleo mineral ao redor da placa de análise.

Os resultados das análises químicas foram tratados estatisticamente através da Análise de Variância e aplicado o teste de Tukey entre as médias a $5 \%$ de probabilidade.

\section{Resultados e Discussão}

As frações de polissacarídeos foram obtidas através de extrações sequenciais. Os rendimentos, grau de esterificação (DE), teores de açúcares totais e proteínas das frações obtidas estão apresentados na Tabela 1. Os rendimentos obtidos variaram de 2,11 a $5,89 \%$.
Tabela 1. Rendimento, grau de esterificação (DE), determinação de açúcares totais e proteínas das frações de polissacarídeos da polpa de gabiroba em diferentes condições.

\begin{tabular}{ccccc}
\hline Frações & $\begin{array}{c}\text { Rendimento } \\
(\boldsymbol{\%})^{1}\end{array}$ & DE $^{2}$ & $\begin{array}{c}\text { Açúcar total }^{3} \\
(\boldsymbol{\%})\end{array}$ & $\begin{array}{c}\text { Proteína }^{4} \\
(\boldsymbol{\%})\end{array}$ \\
\hline F1 & 5,89 & $53,60( \pm 0,08)$ & $84,33( \pm 0,04)$ & $5,65( \pm 0,11)$ \\
F2 & 3,12 & $52,90( \pm 0,07)$ & $74,43( \pm 0,08)$ & $5,82( \pm 0,16)$ \\
F3 & 3,10 & $51,20( \pm 0,10)$ & $75,47( \pm 0,06)$ & $7,33( \pm 0,08)$ \\
F4 & 2,11 & $50,45( \pm 0,1)$ & $78,17( \pm 0,02)$ & $6,25( \pm 0,07)$ \\
\hline
\end{tabular}

1: rendimento das frações em relação ao resíduo insolúvel em álcool; 2: determinado por FTIR; 3: determinado em triplicata pelo método espectrofotométrico ${ }^{[7]} ; 4$ : determinado em triplicata pelo método espectrofotométrico ${ }^{[9]} ;$ *médias ( \pm desvio padrão). Condições de extração: F1 (ácido cítrico $0,5 \% / 50{ }^{\circ} \mathrm{C} / 60 \mathrm{~min}$ ) e $\mathrm{F} 2$ (ácido cítrico $0,5 \% / 100{ }^{\circ} \mathrm{C} / 60 \mathrm{~min}$ ), $\mathrm{F} 3$ (ácido cítrico $5 \% / 50^{\circ} \mathrm{C} / 60 \mathrm{~min}$ ) e $\mathrm{F} 4$ (ácido cítrico $5 \% / 100{ }^{\circ} \mathrm{C} / 60 \mathrm{~min}$ ).

Os rendimentos das frações foram similares aos obtidos para pectinas da polpa do araçá ${ }^{[15]}$. O rendimento foi menor que aquele encontrado para pectinas extraídas da farinha do bagaço da maçã $\tilde{a}^{[16]}$. A fração F4, obtida em condições mais agressivas, apresentou menor rendimento e grau de esterificação mais baixo em relação às demais frações obtidas. A concentração do agente extrator e a temperatura influenciaram no rendimento e na composição do polissacarídeo ${ }^{[17]}$.

O teor de açúcar total das frações de polissacarídeos ficou compreendido entre 74,43 e $84,33 \%$, estando bem próximo dos teores encontrados para polissacarídeos extraídos de frutos do cambuí (Myrciaria tenella) ${ }^{[18]}$. Diferentes fontes de pectinas são descritas contendo materiais protéicos por diferentes autores ${ }^{[19]}$. No entanto os valores encontrados para as frações da polpa de gabiroba podem estar superestimados, pois os compostos fenólicos, presentes nos frutos interferem no método utilizado ${ }^{[20]}$. As características dos diversos polissacarídeos são determinadas através de sua composição monossacarídica e teores de ácidos urônicos ${ }^{[21]}$.

Todas as frações mostram a presença de grupos éter, que correspondem às ligações glicosidicas $(\mathrm{C}-\mathrm{O}-\mathrm{C})$ em picos com absorção entre $1000-1200 \mathrm{~cm}^{-1} \mathrm{e}$ de $\mathrm{H}-\mathrm{C}$ em $1491 \mathrm{~cm}^{-1}$. A presença de compostos fenólicos nas amostras foi indicada pelos picos próximos a $650 \mathrm{~cm}^{-1}$ referente às ligações do anel aromático (Figura 1).

Os picos que aparecem em $2922 \mathrm{~cm}^{-1}$ correspondem ao estiramento das ligações C-H de grupos alquila. A banda larga com máximo a $3400 \mathrm{~cm}^{-1}$ é atribuída ao estiramento de ligações ${ }^{-} \mathrm{OH}$. Todas as frações de pectinas obtidas da gabiroba apresentam bandas de absorção em 1739 a $1747 \mathrm{~cm}^{-1}$ que correspondem aos grupos carboxílicos dos ácidos urônicos esterificados e 1618 a $1629 \mathrm{~cm}^{-1}$ que correspondem aos grupos carboxílicos livres.

A composição monossacarídica e o teor de ácidos urônicos das frações obtidas após hidrolise dos polissacarídeos extraídos do fruto da gabiroba estão apresentados na Tabela 2.

A maior proporção de ácidos urônicos foi detectada na Fração 1 extraída nas condições menos agressivas, que possivelmente extraiu as pectinas da lamela média.

Os polissacarídeos extraídos da gabiroba apresentaram teores consideráveis de ácidos urônicos, arabinose, galactose e ramnose, estando de acordo com os estudos de Mollea e colaboradores ${ }^{[22]}$ que também encontraram quantidade similar de açúcares neutros e sugeriram que a estrutura da maioria das pectinas consiste na cadeia lateral de ramnogalacturano tipo I (RG-I) pela presença destes açúcares. A fucose foi detectada apenas nas frações F3 e F4. A pequena quantidade de fucose é considerada em diversos estudos como contaminante de materiais hemicelulósicos da parede celular. Foi verificada a presença de ramnose em todas as frações. A ramnose é um monossacarídeo que se constitui em pontos de ramificações das cadeias laterais, as quais contêm principalmente arabinose e galactose, podendo conter também outros açúcares como a xilose, manose, glucose e também a fucose ${ }^{[23]}$. 

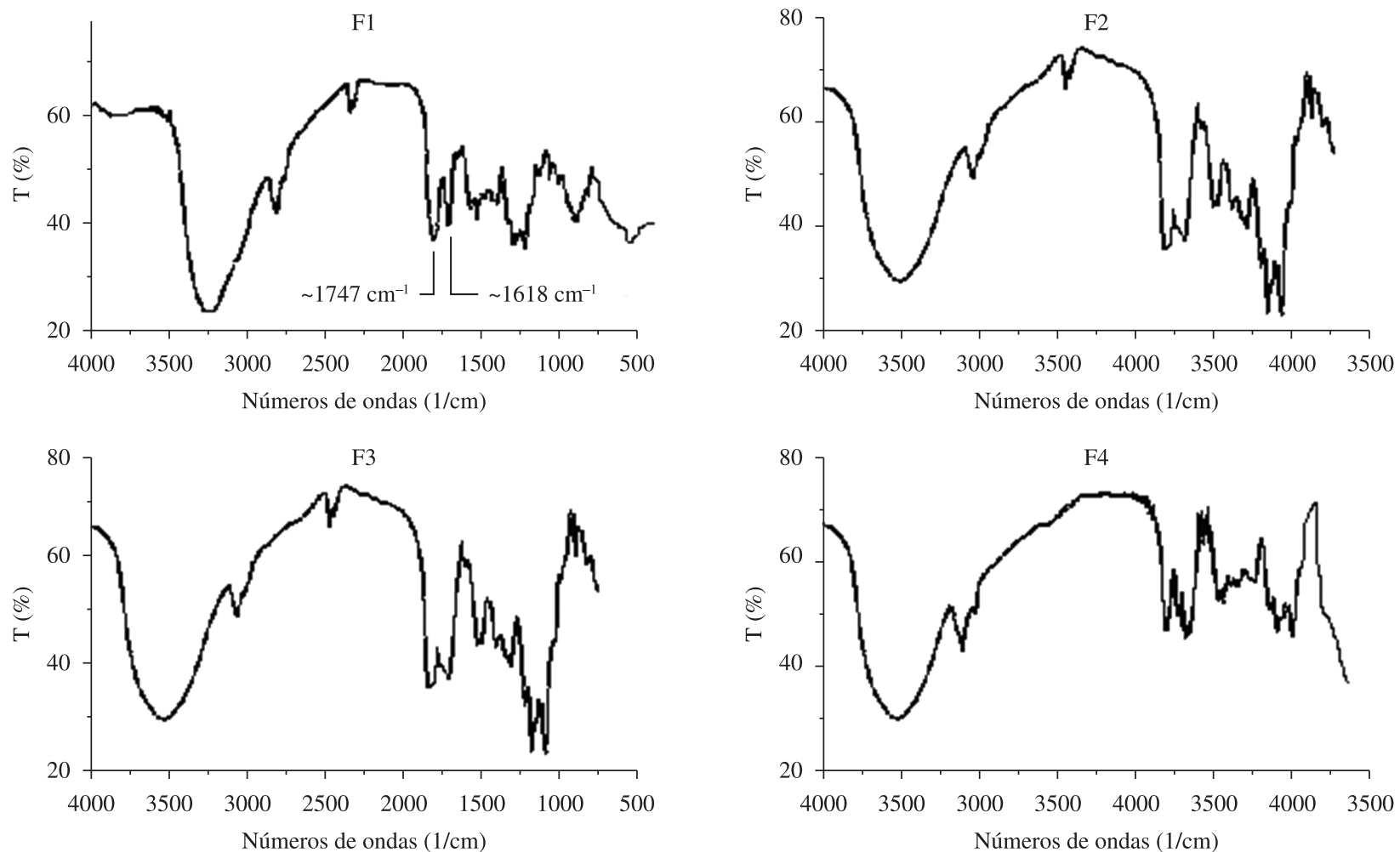

Figura 1. Espectro de infravermelho das frações de pectinas extraídas da gabiroba.

Tabela 2. Composição monossacarídica ${ }^{1}$ das frações de polissacarídeos da polpa de gabiroba.

\begin{tabular}{ccccccccc}
\hline Fração & $\begin{array}{c}\text { Ácidos } \\
\text { Urônico }\end{array}$ & Rha & Fuc & Ara & Xyl & Man & Gal & Glc \\
& & & \multicolumn{7}{c}{ \% } \\
\hline F1 & $22,47( \pm 0,02)$ & $3,07( \pm 0,23)$ & nd & $50,15( \pm 0,62)$ & $4,34( \pm 0,06)$ & $2,39( \pm 0,06)$ & $27,37( \pm 0,45)$ & $12,7( \pm 0,37)$ \\
F2 & $17,09( \pm 0,08)$ & $1,13( \pm 0,16)$ & $0,2( \pm 0,07)$ & $71,62( \pm 0,34)$ & $2,63( \pm 0,06)$ & $0,61( \pm 0,06)$ & $20,99( \pm 0,28)$ & $2,81( \pm 0,19)$ \\
F3 & $17,79( \pm 0,02)$ & $2,16( \pm 0,06)$ & $0,37( \pm 0,08)$ & $61,66( \pm 0,28)$ & $5,13( \pm 0,06)$ & $1,16( \pm 0,21)$ & $22,31( \pm 0,34)$ & $7,22( \pm 0,38)$ \\
F4 & $18,35( \pm 0,04)$ & $2,16( \pm 0,26)$ & nd & $66,71( \pm 0,19)$ & $3,19( \pm 0,06)$ & $1,11( \pm 0,23)$ & $22,93( \pm 0,47)$ & $3,89( \pm 0,29)$ \\
\hline
\end{tabular}

nd: não detectado; 1: determinada por GLC, mol\%; 2: determinado em triplicata ${ }^{[8]}$; *médias ( \pm desvio padrão). Condições de extração: F1 (ácido cítrico $0,5 \%$ /

$50{ }^{\circ} \mathrm{C} / 60 \mathrm{~min}$ ) e $\mathrm{F} 2$ (ácido cítrico $0,5 \%$ / $100^{\circ} \mathrm{C} / 60 \mathrm{~min}$ ), $\mathrm{F} 3$ (ácido cítrico $5 \% / 50{ }^{\circ} \mathrm{C} / 60 \mathrm{~min}$ ) e $\mathrm{F} 4$ (ácido cítrico $5 \%$ / $100^{\circ} \mathrm{C} / 60 \mathrm{~min}$ ).

Após a caracterização físico-química, os polissacarídeos extraídos da polpa de gabiroba foram avaliados quanto ao seu comportamento reológico sob diferentes condições na concentração

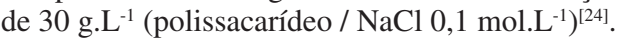

O estudo reológico de matéria prima é de extrema importância no desenvolvimento de novos produtos, para determinar a funcionalidade dos ingredientes e definir a qualidade sensorial através da textura e/ou viscosidade, estabelecendo desta forma as características do produto final. Nas indústrias, os dados reológicos são importantes também para o cálculo de engenharia de processos, englobando grande quantidade de equipamentos tais como agitadores, extrusoras, bombas, trocadores de calor, tubulações e homogeneizadores ${ }^{[25]}$.

As curvas de fluxo típicas dos polissacarídeos da polpa de gabiroba podem ser observadas nas Figuras $2 a$ e $2 b$, as quais mostram uma histerese que é característica de comportamento reológico dependentes do tempo ${ }^{[26]}$.

Os polissacarídeos da polpa da gabiroba apresentam comportamento pseudoplástico. A histerese entre as curva ascendentes e descendentes é um indício de que as frações também apresentam baixos índices de tixotropia.

Muitos fatores afetam as características reológicas das pectinas, assim como a força do gel formado, porém qualquer tratamento que despolimerize as cadeias de pectina refletirá em géis mais fracos, o que pode justificar a diminuição da força dos géis das frações obtidas em condições mais agressivas ${ }^{[27]}$.

Os resultados referentes aos efeitos concomitantes de cálcio e sacarose para géis preparados com todas as frações estão apresentados na Figura 3.

O melhor resultado foi obtido com a fração (F1) extraída nas condições menos agressivas indicando que a diferença na força do gel pode estar relacionada com o tipo de polissacarídeo e tamanho das moléculas extraídas. A temperatura e o tipo de solvente usado para extração podem tornar os polissacarídeos mais vulneráveis à degradação ${ }^{[28]}$.

Todas as frações formaram géis embora com diferentes características. $\mathrm{O}$ valor do módulo de armazenamento $\left(\mathrm{G}^{\prime}\right)$ foi maior que o módulo de perda (G") em todas as faixas de frequência analisada para todas as frações. $\mathrm{O}$ menor poder gelificante foi observado na Fração 4 extraída com ácido cítrico $5 \%$ a $100{ }^{\circ} \mathrm{C}$ (Figura 3b).

Todas as frações formaram géis, embora com diferentes características. O valor do módulo de armazenamento $\left(\mathrm{G}^{\prime}\right)$ foi maior que o módulo de perda (G") em todas as faixas de frequência analisadas para todas as frações. $\mathrm{O}$ menor poder gelificante foi observado na Fração 4 extraída com ácido cítrico $5 \%$ a $100{ }^{\circ} \mathrm{C}$ (Figura 3b). 


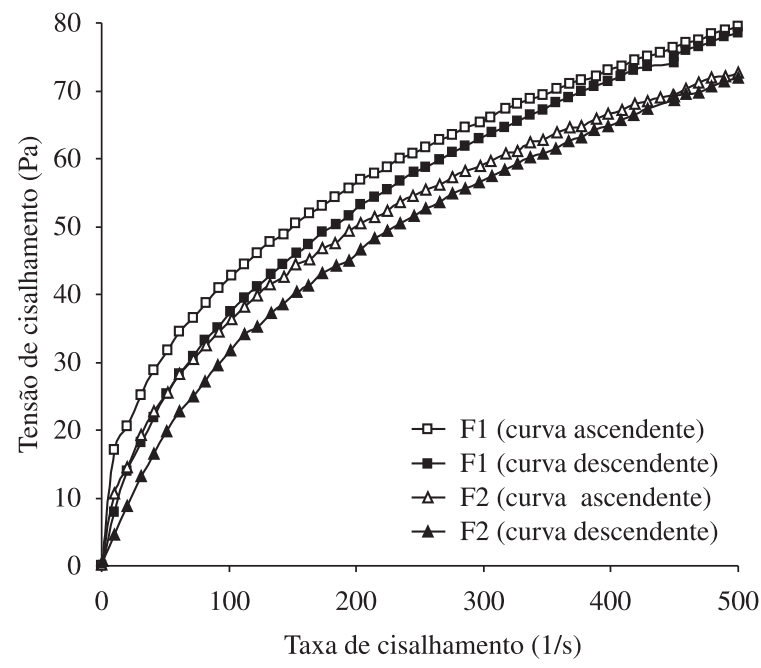

(a)

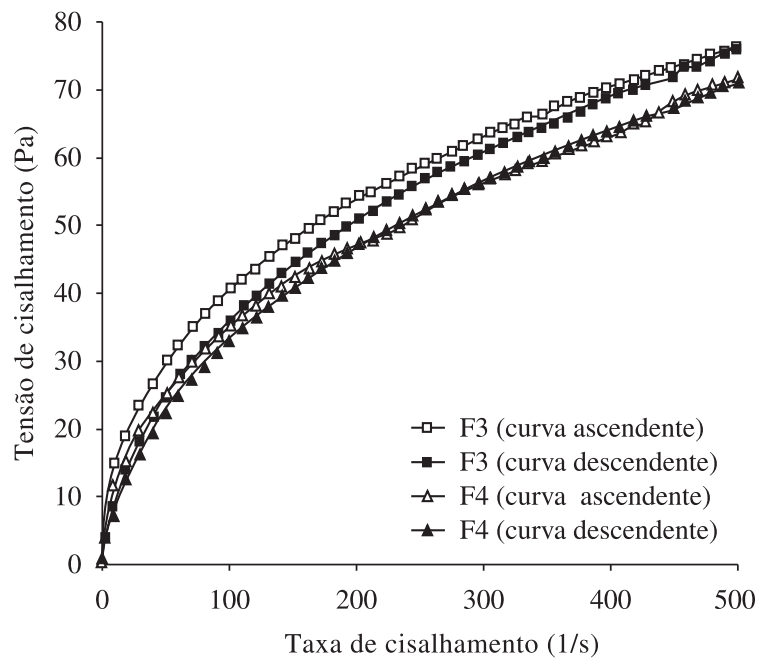

(b)

$$
\neg-(\text { curva ascendente) } \quad \triangleleft-(\text { curva ascendente }) \quad \rightarrow \text { (curva descendente) } \quad \leftarrow \text { (curva descendente) }
$$

Figura 2. a) Curvas de fluxo (ascendente e descendente). Para géis das frações de polissacarídeo da polpa de gabiroba $\mathrm{F} 1(\mathrm{DE}=53,6 \%)$ e F2 (DE = 52,9\%) preparados com cálcio e sacarose $(\mathrm{R}=0,58 / 20 \%)$. b) Curvas de fluxo (ascendente e descendente). Para géis das frações de polissacarídeo da polpa de gabiroba $\mathrm{F} 3(\mathrm{DE}=51,2 \%$ e $\mathrm{F} 4(\mathrm{DE}=50,45 \%)$ preparados com cálcio e sacarose $(\mathrm{R}=0,58 / 20 \%)$.

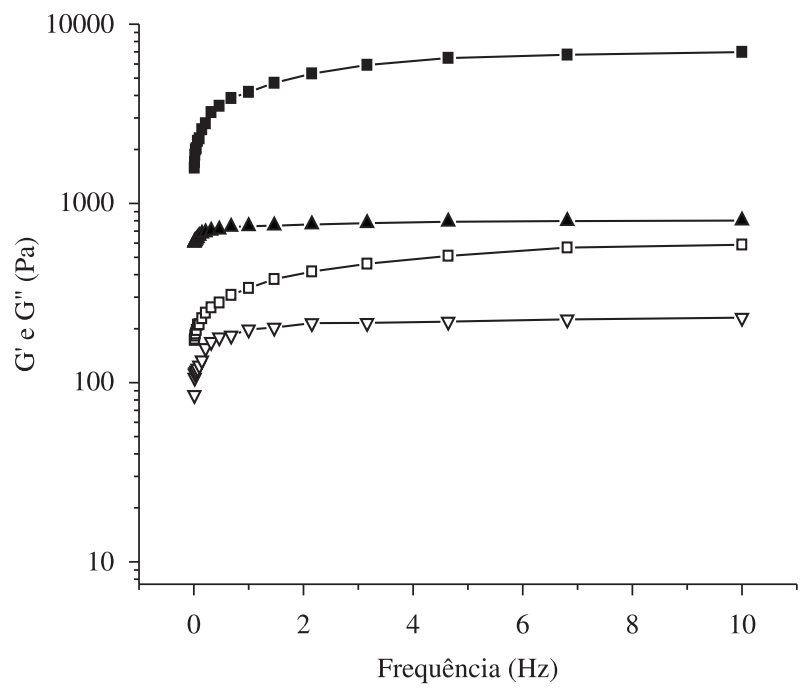

(a)

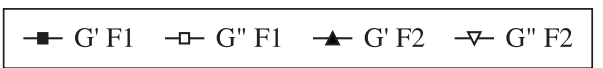

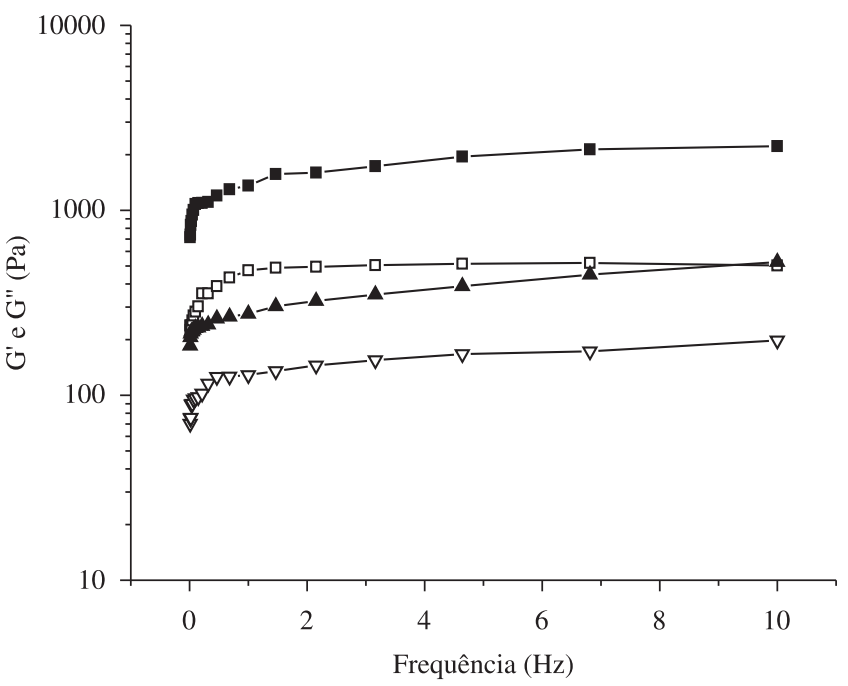

(b)

Figura 3. Efeito da frequência sobre os módulos de armazenamento ( $\left.\mathrm{G}^{\circ}\right)$ e perda (G”). Para géis das frações de polissacarídeo da polpa de gabiroba preparados com cálcio e sacarose $(\mathrm{R}=0,58 / 20 \%)$. a) $\mathrm{F} 1$ (ácido cítrico $0,5 \% / 50^{\circ} \mathrm{C} / 60 \mathrm{~min}$ ) e $\mathrm{F} 2$ (ácido cítrico $0,5 \% / 100^{\circ} \mathrm{C} / 60 \mathrm{~min}$ ). b) $\mathrm{F} 3$ (ácido cítrico $5 \% / 50{ }^{\circ} \mathrm{C} /$ $60 \mathrm{~min}$ ) e F4 (ácido cítrico $5 \% / 100{ }^{\circ} \mathrm{C} / 60 \mathrm{~min}$ ).

As condições drásticas de extração dos polissacarídeos levam à despolimerização e desesterificação, pois, ocorre fragmentação da cadeia poligalacturônica, comprometendo a gelificação das pectinas $^{[29]}$. A estrutura química fina, bem como as unidades de açúcares neutros presentes é de grande importância para a gelificação dos polissacarídeos ${ }^{[30,31]}$. Sharma, Liptay e Le Maguer ${ }^{[32]}$ verificaram que a força dos géis de pectina HM da polpa de tomates, aumenta com o aumento da concentração de sacarose, provavelmente devido ao aumento do número e do tamanho das zonas de junção formadas durante a gelificação ${ }^{[33]}$.

As frações de polissacarídeos também foram avaliadas frente a variações de temperatura (Figura $4 \mathrm{a}$ e $4 \mathrm{~b}$ ).
Com o aumento da temperatura, é sabido que as pontes de hidrogênio são enfraquecidas e as interações hidrofóbicas são fortalecidas ${ }^{[34]}$. Em baixas temperaturas, as pontes de hidrogênio são favorecidas, reforça as zonas de junção e promove a elevação do módulo de armazenamento. Em temperaturas elevadas, a perda da associação por pontes de hidrogênio é compensada com algum reforço das interações hidrofóbicas ${ }^{[35]}$. Os dois efeitos opostos podem explicar o comportamento apresentado pelos géis dos polissacarídeos da polpa de gabiroba com a mudança na temperatura.

$\mathrm{O}$ aquecimento seguido de resfriamento não causa modificações marcantes na textura dos géis. Todas as frações de pectinas extraídas da polpa de gabiroba, mesmo as obtidas nas condições mais drásticas, 


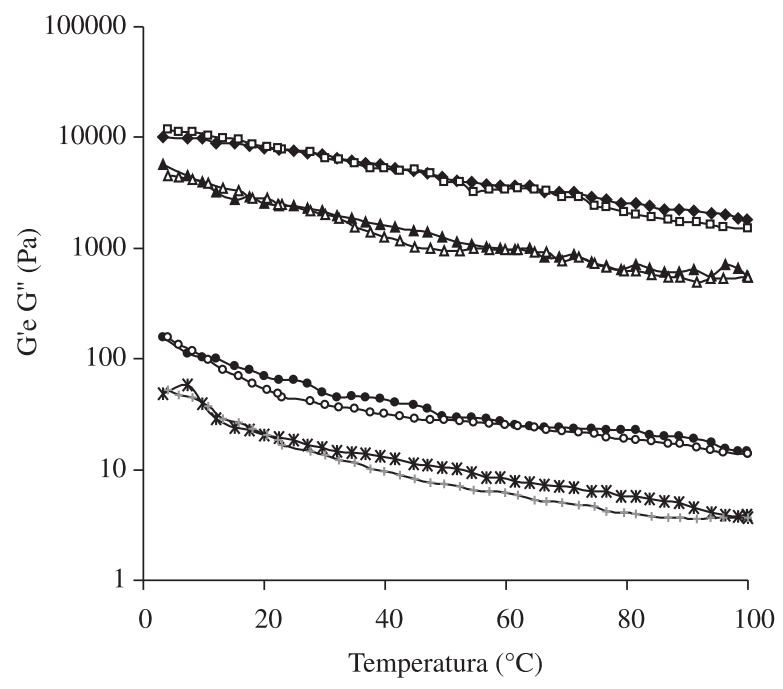

(a)

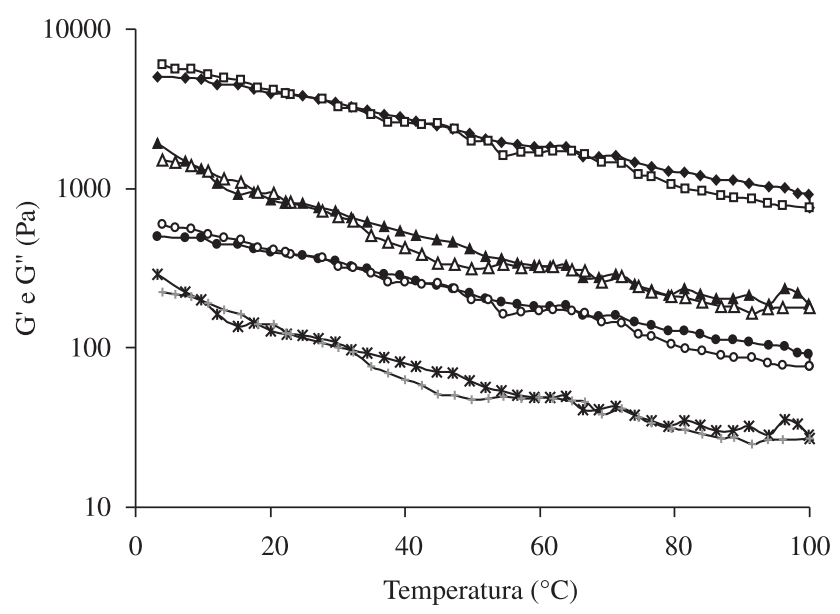

(b)

Figura 4. a) Efeito da temperatura sobre os módulos de armazenamento (G') e perda (G') das frações F1 (DE = 53,6\%) e F2 (DE = 52,9\%) de polissacarídeo da polpa de gabiroba. Para géis preparado com cálcio e sacarose $\mathrm{R}=0,58$ / 20\% das frações. b) Efeito da temperatura sobre os módulos de armazenamento (G') e perda (G”) das frações F3 (DE $=51,2 \%$ e F4 (DE $=50,45 \%)$ de polissacarídeo da polpa de gabiroba.

apresentaram como característica resistência frente às variações de temperatura. Quando submetidas a ciclos de aquecimento e posterior resfriamento estes géis retornam à sua estrutura original.

\section{Conclusões}

As frações de pectinas isoladas da polpa de gabiroba apresentaram-se constituídas principalmente por ácido urônicos, arabinose, galactose e ramnose em diferentes proporções. As condições de extração interferem na composição monossacarídica, grau de esterificação e poder gelificante dos polissacarídeos.

A utilização de extração sequencial de severidade crescente permitiu obter diferentes tipos de pectinas. As condições de extração menos agressivas solubilizaram os polissacarídeos pécticos da parede celular, ligados de modo não covalente, típico de lamela média. As pectinas que estabelecem ligações covalentes com a parede celular foram extraídas nas condições mais agressivas, correspondendo a polímeros altamente ramificados, o que foi constatado pelos teores de ramnose e de açúcares neutros.

$\mathrm{Na}$ concentração de 30 g.L $\mathrm{L}^{-1}$ as pectinas apresentaram comportamento pseudoplástico. Todas as frações de pectinas isoladas formaram géis. Pectinas com baixo grau de esterificação podem formar géis estáveis, na ausência de açúcares, mas requerem a presença de cálcio, que provoca a formação de ligações cruzadas entre as moléculas. As pectinas LM $(<50 \%)$ não necessitam de açúcar, como as HM, para formar gel, porém, a adição de $20 \%$ de sacarose resultou em aumento do caráter sólido do gel, mostrando que o principal fator que condiciona o comportamento reológico das pectinas extraídas da polpa de gabiroba, é o efeito sinérgico entre os co-solutos, relacionado com o grau de esterificação.

Todas as frações de pectinas extraídas da gabiroba, mesmo as obtidas nas condições mais drásticas, apresentaram como característica resistência frente às variações de temperatura. Quando submetidas a ciclos de aquecimento e posterior resfriamento estes géis retornam à sua estrutura original.

\section{Referências Bibliográficas}

1. Lozano, J. E. \& Iglesias, M. T. - J. Food Eng., 62, p.215 (2004).

2. Tromp, R. H.; Kruit, C. G.; Eijk, M. V. \& Rolin, C. - Food Hydrocolloid., 18, p.565 (2003).

3. Rolin, C. - "Pectin", in: Polysaccharides and Their Derivates, Industrial Gums, p.255, Whistler, R. L. \& BeMiller, J. N., Academic Press, San Diego (1993).

4. Bianca, L.; Sadicoff, B. L.; Brandão, E. M.; Elizabete, F.; Lucas, E. F. \& Amorim, M. C. V. - Polímeros, 11, p.41 (2001).

5. Barrera, A. M.; Ramírez, J. A.; González-Cabriales, J. J. \& Vázquez, M. - Food Hydrocolloid., 16, p.441 (2002).

6. Biavatti, M. W.; Farias, C.; Curtius, F.; Brasil, L. M.; Hort, S.; Schuster, L.; Leite, S. N. \& Prado, S. R. T. - J Ethnopharmacol., 93, p.385 (2004).

7. Dubois, M.; Gilles K. A.; Hamilton, J. K.; Rebers, P. A. \& Smith, F. Anal. Chem., 28, p.350 (1956).

8. Filisetti-Cozzi, T. M. \& Carpita, N. C. - Anal Biochem., 197, p.157 (1991).

9. Hartree, E. F. - Anal. Biochem., 48, p.427 (1972).

10. Adams, G. A. - J. Meth. Carbohyd. Chem., 5, p.269 (1965).

11. Wolfron, M. L. \& Thompson, A. - Meth. Carbohyd. Chem., 2, p. 211 (1963).

12. Gorin, P. A. \& Iacomini, M. - Carbohyd. Res. 128, p.119 (1984).

13. Monsoor, M. A. - Carbohyd Polym., 61 p.362 (2005).

14. Fu, J. T. \& Rao, M. A. - Food Hydrocolloid. 15, p.93 (2001).

15. Vriesmann, L. C. - "Acidic Polysaccharides from Psidium cattleianum (Araçá)". In: $5^{\text {th }}$ International Symposium on Natural Polymers and Composites and $8^{\text {th }}$ Brazilian Symposium and Other Wood Components on the Chemistry of Lignins, São Pedro (2004).

16. Marcon, M. V.; Vriesmann, L. C.; Wosiacki, G.; Beleski-Carneiro, E. Polímeros, 15, p.127 (2005). 
17. Pinheiro, E. R. - "Pectina da casca do maracujá amarelo (Passiflora edulis flavicarpa): otimização da extração com ácido cítrico e caracterização físico-química", Dissertação de Mestrado, Universidade Federal de Santa Catarina, Florianópolis, Brasil (2007).

18. Vriesmann1, L. C.; Petkowski, C. L. O.; Carneiro, P. I. B. \& Carneiro, E. B. B. - Publ. UEPG Ci. Exatas Terra, Ci. Agr. Eng., 10, p.41 (2004).

19. Yapo, B. M. - Food Chem, 100, p.1356 (2007).

20. Ângelo, P. M. \& Jorge, N. - Rev. Inst. Adolfo Lutz, 66, p.232 (2007).

21. Rosenbohm, C.; Inge, I.; Christensen, M. I. E. \& Young, N. W. G. Carbohyd Res., 338, p.637 (2002).

22. Mollea, C.; Chiampo, F. \& Conti, R. - Food Chem., 107, p.1353 (2008).

23. Brandão, E. M. \& Andrade, C. T. - Polímeros, 9, p.38 (1999).

24. Grosso, C. R. F. \& Rao, M. A. - Food Hydrocolloid., 12, p.357 (1998).

25. Iagher, F.; Reicher, F. \& Ganter, J. L. M. - J. Biochem. Mol. Biol., 31, p.17 (2002)

26. Bhattacharya, S. - J Food Sci., 64, p.1029 (1999).

27. Canteri-Schemin, M. H. - Braz. Arch. Biol. Techn., 48, p.259 (2005).

28. Alonso-Mougán, M. J. - Food Eng., 55, p.123 (2002).
29. Smout, C.; Sila, N. D.; Truong, S. V.; Ann, M. L. \& Loey, V. - J. Food Eng., 64, p.419 (2005).

30. Fujiü, K.; Miura, K.; Morik, O.; Arikawa, H.; Kianie, T. \& Inoue, K. Dent. Mater. J., 18, p. 430 (1999).

31. Schramm, G. "Reologia e reometria: fundamentos teóricos e práticos", Artliber, São Paulo (2006).

32. Sharma, S. K.; Liptay, A. \& Le Maguer, M. - Food Res. Int., 30, p.543 (1998).

33. Tsoga, A., Richardson, R. K. \& Morris, E. R. - Food Hydrocolloid., 18, p.907 (2004).

34. Lopes, S. J. A.; Gonçalves, M. P. \& Rao, M. A. - Carbohyd Polym., 23, p.77 (1994).

35. Evageliou, V.; Richardson, R. K. \& Morris, E. R. - Carbohyd Polym., 42, p.245 (2000).

Enviado: $20 / 02 / 10$

Reenviado: $24 / 05 / 10$

Aceito: $14 / 06 / 10$

DOI: 10.1590/S0104-14282010005000056 